Infect Dis Clin North Am. 2015 December ; 29(4): 679-697. doi:10.1016/j.idc.2015.07.009.

\title{
Pneumococcal Disease in the Era of Pneumococcal Conjugate Vaccine
}

\author{
Inci Yildirim, MD, MSc ${ }^{\mathrm{a}, \mathrm{b}}$, Kimberly M. Shea, PhD, MPH ${ }^{\mathrm{b}}$, and Stephen I. Pelton, MD ${ }^{\mathrm{a}, \mathrm{b}}$ \\ aSection of Pediatric Infectious Diseases, Department of Pediatrics, Boston University Medical \\ Center, Boston, Massachusetts \\ bepartment of Epidemiology, Boston University, School of Public Health, Boston, Massachusetts
}

\section{SYNOPSIS}

Universal immunization of infants and toddlers with PCVs over the past 15 years has dramatically altered the landscape of pneumococcal disease. Decreases in IPD, all cause pneumonia, empyema, mastoiditis, acute otitis media and complicated otitis media have been reported from multiple countries where universal immunization has been implemented. The introduction of the vaccine has also led to expanded understanding of pneumococcal disease; observations have confirmed that most pneumococci are transmitted from children to adults, not all pneumococcal serotypes are equal in terms of common clinical syndromes, likelihood of antibiotic resistance, or likelihood of progression to disease once colonization occurs. Children with comorbid conditions have higher rates of pneumococcal disease and increased case fatality rates compared to otherwise healthy children, and protection for the most vulnerable pediatric patients will require new strategies to address the underlying host susceptibility and the expanded spectrum of serotypes observed.

\section{Keywords}

Pneumococcal disease; Pneumococcal conjugate vaccine; Invasive pneumococcal disease; Pneumococcal meningitis; Pneumococcal pneumonia

The universal immunization of infants and toddlers with pneumococcal conjugate vaccine (PCV) in the United States beginning in 2000 heralded a new era for pneumococcal disease prevention. Conjugate vaccines were immunogenic in young infants, prevented vaccine type invasive pneumococcal disease (IPD), pneumonia and otitis media, and decreased nasopharyngeal colonization with vaccine serotypes leading to a herd effect that impacted all age groups. However, new challenges emerged that would eventually lead to second

Correspondence to: Stephen I. Pelton.

AUTHOR CONTACT INFORMATION

Inci Yildirim Maxwell Finland Laboratory for Infectious Diseases 670 Albany Street, Boston MA 02118 yildirim@bu.edu Kimberly M.Shea Department of Epidemiology, Room 322, Boston University School of Public Health, 715 Albany Street, Boston, MA 02118,kimshea@bu.edu

Stephen I. Pelton Maxwell Finland Laboratory for Infectious Diseases, 670 Albany Street, Boston MA 02118 spelton@bu.edu

Publisher's Disclaimer: This is a PDF file of an unedited manuscript that has been accepted for publication. As a service to our customers we are providing this early version of the manuscript. The manuscript will undergo copyediting, typesetting, and review of the resulting proof before it is published in its final citable form. Please note that during the production process errors may be discovered which could affect the content, and all legal disclaimers that apply to the journal pertain. 
generation conjugates that included a larger number of serotypes to address both replacement disease (increases in disease due to nonvaccine serotypes) as well as providing more expansive coverage for the global community. Post-licensure studies provided new insights into the importance of serotype distribution among carriage isolates and how the event-to-carrier ratio for a specific serotype permits us to understand the substantial decline in IPD in the absence of a decline in overall pneumococcal colonization. The limitation of current diagnostic tools for pneumococcal pneumonia became apparent from the discord between the prevalence of diagnosed pneumococcal pneumonia in studies of pediatric pneumonia compared to the observed decline in all-cause pneumonia associated with pneumococcal vaccine uptake in the community. ${ }^{1,2}$ Despite the progress in prevention, pneumococcal disease continues to disproportionately impact children in low income countries and those with comorbid conditions (in high income countries), and remains a major cause of mortality and morbidity.

\section{Epidemiology}

Nasopharyngeal colonization with Streptococcus pneumoniae is an initial step in the pathogenesis of pneumococcal disease. Asymptomatic carriage is common with reported prevalence ranging from $11 \%$ to $93 \%$; carriage varies with age, environment, the presence of upper respiratory infections and population studied. ${ }^{3,4}$ Risk factors for pneumococcal carriage include age younger than 2 years, exposure to overcrowding and household smoking, attendance at out-of-home child care, winter season, and lack of breastfeeding. ${ }^{5}$ Initial acquisition of pneumococci occurs earlier in low income countries, (as early as the first month of life) compared to high income countries and peaks at 2-3 years of age., 4 Among school-aged children, $20 \%-60 \%$ may be colonized whereas only $5 \%-10 \%$ of adults are colonized. The duration of carriage also varies and is generally longer in children than adults. ${ }^{6}$ The relationship of carriage to the development of natural immunity is poorly understood, but the prevalence of nasopharyngeal carriage declines over time suggesting that colonization elicits protection. ${ }^{7}$ The impact of conjugated vaccines on pneumococcal carriage has been dramatic; vaccination has resulted in near elimination of vaccine serotypes and increased prevalence of nonvaccine serotypes, with little change in the overall rate of pneumococcal colonization. Changing serotype distributions in the nasopharynx has led to a subsequent reduction in IPD as the majority of nonvaccine serotypes have a lower likelihood of causing disease once colonization has been established, as well as decreased transmission of vaccine serotypes to under- or unimmunized children and adults, also resulting in lower rates of IPD in under- or unimmunized children and adults. ${ }^{8}$

Most S. pneumoniae serotypes have been shown to cause serious disease, but of the 92 known pneumococcal serotypes, 10 serotypes account for nearly $62 \%$ of invasive disease worldwide. ${ }^{9}$ The rank order and serotype prevalence differ over time, by age group and by geographic area. In the United States, prior to widespread use of 7-valent pneumococcal conjugate vaccine (PCV7), serotypes 4, 6B, 9V,18C,19F and 23F were the most common serotypes isolated from blood or cerebrospinal fluid (CSF) and were responsible for $80 \%$ of the invasive infections in children younger than 5 years of age. ${ }^{10}$ Serotypes $6 \mathrm{~B}, 9 \mathrm{~V}, 19 \mathrm{~F}$, and $23 \mathrm{~F}$ also accounted for approximately $80 \%$ of penicillin-nonsusceptible isolates. Pneumococcal disease is mostly episodic, however pneumococci are transmitted from 
person to person by respiratory droplets and outbreaks have occurred in overcrowded enclosed settings such as military barracks, homeless shelters, prisons and childcare facilities most often due to serotype 1,5 or $8.5,11$

The age distribution of IPD has changed with the universal immunization of infants and toddlers with conjugate vaccine. Before 2000, IPD was seen most often in children under 5 years old and had a second peak after age $65 .{ }^{12}$ Currently, the highest rates of IPD are seen in persons over age 65 years with a smaller peak in children under 5 (Figure 1) and an increasing proportion of pediatric cases in the 5 to 18 year age group. ${ }^{7,12,13}$ Type-specific antibodies are passively transferred from the mother and are protective for the first months of life in full-term infants. The peak incidence of IPD in children occurs between 6 to 11 months of age as maternal antibody declines. ${ }^{14}$ In neonatal pneumococcal infections the organism is usually acquired from the maternal genital tract, and both early-onset and lateonset disease has been identified. Bacteremia without a known site of infection is the most common presentation of IPD among children 2 years of age and younger, accounting for approximately $70 \%$ of invasive disease in this age group, whereas bacteremic pneumonia accounts $12 \%-16 \%$ of cases. ${ }^{7}$ Before routine use of pneumococcal conjugate vaccine, meningitis was most commonly seen in children between age 6 to 18 months with an approximate rate of 10 cases per 100,000 population and an $8 \%$ case-fatality rate among children in the United States. ${ }^{15}$ The majority of cases with pneumococcal bone and joint infections are children 3 to 34 months old, while the majority of pneumococcal pneumonia cases are seen in children between 3 and 60 months of age. ${ }^{7}$ Pneumococci are also a common cause of acute otitis media (AOM) and are detected in $28 \%-55 \%$ of middle ear aspirates. The peak incidence of AOM in otherwise healthy children is between 6 and 18 months and by age 12 months, more than $60 \%$ of children have had at least one episode of acute otitis media.

The impact of widespread PCV immunization of children on IPD has been substantial in all age groups. Figure 2 details the decline in PCV7 serotypes after introduction of PCV7 in Denmark, the increase and subsequent decline in PCV13 serotypes following use of PCV7 and subsequent switch to PCV13, and the rise in disease attributable to nonvaccine serotypes. ${ }^{16}$ In the United States results from the Active Bacterial Core surveillance (ABCs) program conducted by the Centers for Disease Control and Prevention (CDC) indicated that rate of IPD, in all age groups combined, dropped from an average of 24.3 cases per 100,000 persons in the prevaccine years (1998 and 1999) to 17.3 cases per 100,000 persons after the vaccine's introduction in 2001. ${ }^{17}$ Invasive disease caused by vaccine serotypes declined more than $99 \%$ in children under 5 years of age, resulting in a $75 \%$ decline in overall IPD in this age group, which resulted from direct effects in vaccine recipients and herd effect in unvaccinated children. ${ }^{17,18}$ Since serotypes included in PCV7 accounted for the majority of antibiotic-resistant strains, the proportion of resistant isolates also declined initially. The rate of disease caused by penicillin-nonsusceptible isolates dropped by $35 \%$ compared to that in the prevaccine year 1999 ( 6.3 cases per 100,000 individuals to 4.1 cases per 100,000 individuals). ${ }^{17}$ After almost a decade of PCV7 use, some studies have reported an increasing incidence of IPD primarily caused by non-PCV7 serotypes (replacement disease). Singleton et $\mathrm{al}^{19}$ reported that replacement disease resulted in an incidence of IPD among native Alaskan native children that exceed the incidence in the pre-PCV7 era. Yildirim et al ${ }^{13}$ 
identified that despite a sustained decrease in the overall incidence of IPD in Massachusetts, disease due to non-PCV7 serotypes such as 19A, 7F and 15B/C increased and caused the majority of IPD cases in children during the period 2007 to 2009 (Figure 3). Emerging nonvaccine serotypes, mostly $1,7 \mathrm{~F}, 12 \mathrm{~F}, 19 \mathrm{~A}, 22 \mathrm{~F}$ and $24 \mathrm{~F}$ were associated with an increase in IPD rates among children in Europe. ${ }^{20,21}$ The increase in disease due to nonvaccine serotypes was not limited to IPD; pneumococcal empyema increased in both United States and Europe ${ }^{22-24}$, a rise in cases of mastoiditis and unresponsive otitis media due to serotype $19 \mathrm{~A}$ was observed ${ }^{25}$, and increasing cases of pneumococcal hemolytic uremic syndrome ${ }^{26,27}$ were reported.

The erosion of PCV7 effectiveness for IPD from an increase in disease due to nonvaccine serotypes and the increasing concern about rising case numbers of empyema, mastoiditis and unresponsive otitis media led to the introduction of a second generation, 13-valent conjugate vaccine (PCV13) targeting 6 additional serotypes in 2010 (1,3,5,6A,7F,19A). Within 6 months after introduction of PCV13, a rapid reduction in PCV13 type IPD was observed in children younger than 5 years who were targeted for vaccination. Moore et al. ${ }^{28}$ reported that compared with what would have been predicted in the absence of PCV13, overall incidence of IPD in June, 2013, was 64\% lower, whereas incidence of disease due to the unique PCV13 serotypes declined 93\%. A similar reduction, through herd protection, was observed among adults. In all age groups, changes in incidence were driven principally by declines in IPD caused by serotypes 19A and 7F.

\section{Pneumococcal Disease in Children with Comorbid Conditions}

Several recent studies have demonstrated that although pneumococcal vaccination has substantially reduced IPD incidence in all risk groups, persons with immunodeficiency or chronic medical conditions continue to suffer a disproportionate burden of pneumococcal disease. ${ }^{29-32}$

For example, in HIV-infected adults the incidence of PCV7-type IPD decreased by $88 \%$ following the introduction of PCV7 in children, but the rate of PCV7-type IPD in this population persists at 40 -fold higher than the rate among healthy adults in the same age group. ${ }^{33}$ IPD risk is highest among children and adults with immunocompromised immune systems due to congenital or acquired immunodeficiency, immunosuppressive therapy, functional (e.g., sickle cell disease) or anatomic asplenia, chronic renal failure, or nephrotic syndrome. ${ }^{7,32,34}$ In immunocompromised adults $18-64$ years of age, the incidence of IPD is $100-400$ cases per 100,000 ${ }^{30,33}$ compared with approximately 9 cases per 1000,000 in otherwise healthy adults in that age group. ${ }^{31}$ Similarly, the risk of IPD in children under 5 years of age and 5 to 17 years of age with immunocompromising medical conditions is $\sim 4$ fold to $\sim 40$-fold higher compared with otherwise healthy children of the same age. ${ }^{29}$ In addition to being more frequent, the outcome of IPD in children with comorbid conditions is also less favorable. Van Hoek et al reported increased case fatality rates, specifically in children with asplenia and chronic cardiac, pulmonary, and liver disease. ${ }^{32,35}$

Children and adults with chronic cardiovascular disease, pulmonary disease, liver disease, kidney disease, and cerebrospinal fluid (CSF) leakage continue to be at increased risk for 
IPD compared with persons without these conditions. ${ }^{35-37}$ More recently, asthma and diabetes have also been identified as independent risk factors for IPD in both children and adults. ${ }^{29,30,38}$ Several large population-based studies have recently been conducted in efforts to better characterize the magnitude of risk associated with individual underlying medical conditions. Results from these studies have indicated that the risk of IPD in immunocompetent children who have one or more of the chronic medical conditions for which the Advisory Committee on Immunization Practices (ACIP) currently recommends pneumococcal vaccination ${ }^{35}$ as being 2 -fold to 4 -fold higher ${ }^{29}$, and risk of IPD in adults as 3 -fold higher. ${ }^{30}$ In addition, the risk of IPD in immunocompetent persons substantially increases with the accumulation of concurrent chronic illnesses (risk stacking). ${ }^{31}$ The risk of IPD in immunocompetent persons with two or more chronic illnesses approximate those in persons with high risk conditions, and the risk of IPD in immunocompetent persons with three or more chronic illnesses often exceeds the risk in persons with high-risk conditions (Figure 4). ${ }^{29}$

In part, the serotype distribution in children with comorbid conditions explains the persistence of increased risk. Several studies have identified an increased proportion of IPD due to non-vaccine serotypes in children with comorbid conditions. ${ }^{32,39}$ Ladhani et al. ${ }^{40}$ reported that children with comorbid conditions have a broader spectrum of serotypes including those with a lower likelihood of causing disease after colonization (Figure 5). These observations have important implications and provide support for the ACIP recommendations for immunization with 23 -valent pneumococcal polysaccharide vaccine in children with specified at-risk conditions. ${ }^{12}$

\section{Laboratory Diagnosis}

Conventional practice for the diagnosis of pneumococcal disease continues to rely on the isolation of Streptococcus pneumoniae in culture from blood or normally sterile body sites such as pleural fluid, CSF, synovial fluid, or cardiac vegetation. Pneumococcal isolation is jeopardized by prior antibiotic therapy, therefore cultures should be obtained before antimicrobial treatment is started. The bacterium typically grows within 18-24 hours of inoculation of the culture media. In his historical study from early $20^{\text {th }}$ century Rosenow ${ }^{41}$ found that $90 \%$ of patients with pneumococcal pneumonia had positive blood cultures. However rates of positive blood culture depend on the technique, volume of the sample, etc. and can be only 3\%-8\% among adults hospitalized with pneumonia, and are even lower in children. In more recent studies conducted before widespread use of pneumococcal vaccines, around $88 \%$ of the patients with pneumococcal meningitis were reported to have positive blood cultures. ${ }^{42}$

The most recent developments in laboratory diagnosis of pneumococcal infections have occurred with antigen detection assays. Rapid antigen tests such as latex agglutination (LAT) or enzyme immunoassay tests targeting capsular polysaccharide have been used in testing sputum, CSF, urine but found to be poorly sensitive and not specific enough to be of clinical value, especially in children. An immunochromatographic urine antigen assay (Binax NOW Streptococcus pneumoniae test; Binax Inc., Portland, ME) targeting the C polysaccharide cell wall antigen that is common to all strains of S. pneumoniae was shown 
to be promising for diagnosis of community-acquired pneumonia in adult patients, however leads to high false positive results. In one study, $51 \%$ of healthy children tested positive ${ }^{43}$ in the absence of any clinical manifestations of pneumonia or bacteremia, presumably due to nasopharyngeal colonization only. The same test when used to on CSF samples was $100 \%$ sensitive for identification of S. pneumoniae in pyogenic CSF with very high specificity compared with the nonpneumococcal cases. ${ }^{44,45}$

The role of nucleic acid amplification tests in diagnosis of pneumococcal infections has yet to be fully clarified. Polymerase chain reaction (PCR)-based techniques have the advantage of detecting both the viable and nonviable $S$. pneumoniae in clinical samples and may be used alone or in combination with other tests for diagnosis of pneumococcal infections. PCR detects S. pneumoniae in blood samples with a sensitivity ranging from $29 \%$ to $100 \%$ in children with pneumonia. ${ }^{46}$ When applied to CSF samples the sensitivity and specificity have been reported as $92 \%-100 \% .{ }^{47}$ Quantitative PCR has also suggested as a tool to distinguish colonization from infection, with a higher bacterial burden among individuals with in invasive pneumococcal disease. However the value of quantitation appears more promising in adults than in children.

Matrix-assisted laser desorption ionization time-of-flight mass spectrometry (MALDI-TOF MS) has been adapted for the routine identification of microorganisms in clinical microbiology laboratories in the past 10 years and theoretically has the potential to identify any organism from a positive blood culture. ${ }^{48}$ Although this technology is reported to reduce the cost and time to result of bacterial identification, ${ }^{49}$ blood culture samples require processing prior to MALDI-TOF MS analysis to remove nonbacterial proteins such as serum proteins and hemoglobin and it fails to reliably differentiate Streptococcus pneumoniae from Streptococcus mitis. ${ }^{50}$

Other rapid molecular methods using real-time multiplexed nucleic acid amplification tests [e.g. Film Array system from IdahoTechnology (Salt Lake City, UT, USA) $]^{51}$ are being developed to decrease the detection time and have been adopted for diagnosis of pneumococcal infections and infections caused by other bacteria (e.g. Staphylococcus aureus). These approaches comprise a potential point-of-care diagnostic tool with high sensitivity and specificity in direct identification of pneumococci especially from positive blood culture bottles. ${ }^{52}$ However further studies analyzing the clinical significance of positive results in samples from patients with pneumococcal infections are warranted.

However, despite developments in laboratory diagnostics, a microbiological diagnosis is still not made in most cases of IPD, particularly for pneumococcal pneumonia largely as a result of the problems associated with obtaining high-quality lower respiratory tract samples for testing and with uncertainty regarding the differentiation of infection from colonization. The microscopic demonstration of numerous Gram-positive diplococci in a sputum sample with $<10$ squamous epithelial (SEC) cells and $>25$ polymorphonuclear (PMN) cells per lowpower field (magnification, $\times 100$ ) or $\geqslant 10$ leukocytes for each SEC is strongly suggestive of pneumococcal pneumonia (Figure 6) ${ }^{53}$ Transthoracic needle aspiration of infected lung parenchyma has the potential to improve the diagnostic yield, especially in children who may not produce sputum, however the procedure is not justified in many patients with 
uncomplicated pneumonia. ${ }^{54}$ Taken together, there is no easy way to establish the diagnosis of nonbacteremic pneumococcal infections and increased efforts should be directed toward development of more sensitive and specific new diagnostic tools to help clinicians diagnose especially pneumococcal pneumonia.

\section{Treatment}

Treatment of pneumococcal disease requires an approach that considers site of infection, antimicrobial susceptibility patterns in the community, and severity of illness.

\section{Pneumococcal Meningitis}

Pneumococcal meningitis is associated with the greatest mortality and morbidity and requires effective therapy that will rapidly sterilize the central nervous system as well as limit the inflammatory response and its potential impact on cerebral blood perfusion, hypoxia, and cell death. Initial assessment must include evaluation of circulatory function and fluid status as sepsis will frequently also be present. Attention to vital signs, mental status, urine output, and electrolyte management is critical for optimizing outcomes. Sufficient fluid should be provided to maintain normal systolic blood pressure, tissue perfusion, and urine output. Evaluation for inappropriate antidiuretic hormone secretion, manifest as hyponatremia, should be also included in the initial assessment.

In otherwise healthy children, initial antibiotic selection should include coverage for most common pathogens - S. pneumoniae and Neisseria meningitidis in children over 3 months of age and S. pneumoniae, Group B streptococcus, Listeria monocytogenes and enteric Gram negative bacteria in children younger than 3 months of age. Initial therapy should be administered IV to achieve adequate serum and CSF concentrations; intraosseous administration is appropriate, in unstable children, if venous access cannot be established. According to the 2004 Infectious Diseases Society of America (IDSA) practice guidelines for bacterial meningitis, vancomycin plus either ceftriaxone or cefotaxime is recommended for suspected bacterial meningitis. ${ }^{55} \mathrm{We}$ continue to use this combination despite the decline in serotype 19A prevalence in the community as most recent data continues to identify cases of 19A disease in children. ${ }^{32}$ As vancomycin penetrates the CNS poorly, especially when administered with dexamethasone, higher dosing ( $70 \mathrm{mg} / \mathrm{kg} /$ day) is recommended initially (Table 1) specifically in children $<12$ years of age ${ }^{56}$ Once the etiology is established and susceptibility determined, cefotaxime or ceftriaxone alone is adequate when susceptible pneumococci are causative. When the minimal inhibitory concentration for cefotaxime is increased (MIC $\geq 0.5 \mathrm{ug} / \mathrm{ml}$ )(considered intermediate-resistance), a higher dosing of cefotaxime $(300 \mathrm{mg} / \mathrm{kg} /$ day) in combination with vancomycin $(70 \mathrm{mg} / \mathrm{kg} /$ day) may achieve more rapid sterilization of the CSF (Table 2). ${ }^{57}$ Although now less common since the introduction of PCV13, if high level resistance to cefotaxime or ceftriaxone is present (MIC $\geq 2 \mathrm{ug} / \mathrm{ml}$ ), rifampin added to the regimen enhances the bactericidal activity in the CSF. Meropenem has been studied in children with bacterial meningitis and found to have clinical and microbiologic outcomes similar to those of third generation cephalosporins. Meropenem may also be effective in patients with pneumococcal meningitis caused by highly penicillinand cephalosporin- resistant strains when the isolate is meropenem susceptible. Repeat lumbar puncture (LP) to evaluate sterilization of the CNS is not routinely performed. 
Indications for repeat LP would include a failure to improve after 48 to 72 hours of antimicrobial therapy or possibly in the setting where dexamethasone has been administered and a highly resistant pneumococci was isolated from CSF as the use of steroids potentially could cloud the assessment of clinical response.

Reducing inflammation in the CNS has also been demonstrated to be of benefit in animal models, children with meningitis due to Haemophilus influenza type $B$ and adults with pneumococcal meningitis. However, controversy persists regarding its use in children with pneumococcal meningitis. IDSA guidelines recommend adjunctive dexamethasone in a dosage of $0.15 \mathrm{mg} / \mathrm{kg}$ q6h for 2-4 days, initiated 10-20 minutes before (or at least concomitant with) the first antimicrobial dose. In contrast, AAP Committee on Infectious Diseases suggests that dexamethasone therapy be considered for infants and children older than six weeks with pneumococcal meningitis after weighing the potential risks and benefits. ${ }^{58}$ Our current approach is based on a case-by-case analysis, however more often than not we favor its use in children with suspected bacterial meningitis and mental status changes or neurological deficits on presentation. Adverse events have been uncommonly associated with use of dexamethasone in bacterial meningitis; gastrointestinal bleeding is the most common and recently delayed cerebral thrombosis after initial good recovery from pneumococcal meningitis has been reported in adults. ${ }^{59}$

\section{Pneumococcal pneumonia}

The treatment of pneumococcal pneumonia presents a different challenge than that of meningitis as achieving sufficient drug concentration in the lung and alveolar fluid is less challenging that in the CNS. Beta-lactam antibiotics (e.g., amoxicillin, ceftriaxone) achieve high levels in the respiratory tract such that pneumococci with minimal inhibitory concentration of less than $8 \mathrm{ug} / \mathrm{ml}$ for penicillin and less than $4 \mathrm{ug} / \mathrm{ml}$ for ceftriaxone can be successfully treated. For pneumococcal pneumonia without complications, including disease caused by penicillin- and ceftriaxone-resistant pneumococci, amoxicillin is the drug of choice if the organism's MIC is less than $8 \mathrm{mcg} / \mathrm{mL}$. For pneumococci with an MIC of 8 $\mathrm{mcg} / \mathrm{mL}$ or higher, ceftriaxone (if MIC is less than $4 \mathrm{mcg} / \mathrm{mL}$ ) is first choice. Recovery from pneumococcal pneumonia may be prolonged especially when empyema or necrotizing pneumonia is present. The presence of cavitation, pneumoatocele, or empyema requires a different approach. Ceftriaxone and vancomycin, in combination, is currently the initial regimen of choice with modification based on results of cultures. As well, such cases may require chest tube drainage or video assisted thoracic surgery. Nearly all patients recover completely, however the course may be prolonged with fever lasting as long as 3 weeks as well as prolonged hospitalization. ${ }^{60}$

During the last decade increasing number of cases of pneumococcal related hemolytic uremic syndrome have been reported, most often associated with pneumonia and empyema. ${ }^{26,27}$ The cases appear to occur in mostly infants and toddlers, often are caused by serotype 19A (but not exclusively) and are likely to progress to severe renal and hematologic disease and often require dialysis and platelet and packed red blood cell transfusions. ${ }^{27}$ 


\section{Prevention}

Pneumococcal vaccines, both polysaccharide and conjugate formulations, are recommended by the ACIP for prevention of pneumococcal disease. Currently available 23-valent polysaccharide vaccine (PPSV23; Pneumovax, Merck \& Company, Inc.) was licensed in the US in 1983 and contains purified polysaccharide antigen ( $25 \mathrm{mcg}$ of each per dose) of 23 serotypes $(1,2,3,4,5,6 \mathrm{~B}, 7 \mathrm{~F}, 8,9 \mathrm{~N}, 9 \mathrm{~V}, 10 \mathrm{~A}, 11 \mathrm{~A}, 12 \mathrm{~F}, 14,15 \mathrm{~B}, 17 \mathrm{~F}, 18 \mathrm{C}, 19 \mathrm{~A}, 19 \mathrm{~F}, 20$, $22 \mathrm{~F}, 23 \mathrm{~F}$, and $33 \mathrm{~F}$ ) that accounted for $90 \%$ of the invasive pneumococcal disease at the time of licensure. ${ }^{7}$ PPSV 23 induces antibody response in $~ 80 \%$ of healthy adult vaccinees within 2 to 3 weeks of immunization and elevated antibody levels persist for at least 5 years. This vaccine has been shown to be effective against invasive pneumococcal disease with efficacy between $56 \%$ to $86 \%$ in healthy adults. ${ }^{61}$ However capsular polysaccharides used in the vaccine are T-independent immunogens and induce limited antibody response in young children, specifically under 2 years of age, which is the age group with highest incidence of pneumococcal infections. ${ }^{62}$ Additional major caveats in pediatric age group are polysaccharide antigens do not induce immunologic memory, fail to prime for booster response with the subsequent exposure, serotype-specific antibody levels decline rapidly following the immunization within 3-5 years, immunization does not reduce nasopharyngeal colonization and efficacy against mucosal surface infection such as nonbacteremic pneumonia and otitis media is limited. Despite these limitations, the use of PPSV23 is still recommended for US children with increased risk of invasive pneumococcal disease, such as those with sickle cell disease or HIV infection, after they complete their conjugated vaccine series (Table 3). ${ }^{63}$

To address the problem of decreased immunogenicity, polysaccharide antigens have been covalently linked to protein carriers to induce T-helper cell response. In February 2000, a 7valent pneumococcal polysaccharide-protein conjugate vaccine (PCV7, Prevnar, Wyeth [Collegeville, PA, USA]) was licensed in the US and contained serotypes 4, 6B, 9V, 14, 18C, 19F, and 23F. ${ }^{7}$ A prelicensure clinical efficacy trial of PCV7 demonstrated $97.4 \%$ efficacy against IPD caused by vaccine serotypes among fully vaccinated infants. ${ }^{64}$ The safety, efficacy, and effectiveness in practice of PCV7 and other pneumococcal conjugate vaccines has been established in multiple settings in both high income and low income countries. ${ }^{65}$ Data from the CDC's ABCs program suggested that widespread use of PCV7 has resulted in a $99 \%$ decrease in disease caused by vaccine serotypes and serotype $6 \mathrm{~A}$, a serotype against which PCV7 provides some cross-protection. PCV7 resulted in 20\% fewer episodes of chest X-ray confirmed pneumonia, ${ }^{2} 7 \%$ fewer episodes of acute otitis media ${ }^{66}$ and $20 \%$ fewer tympanostomy tube placements among vaccinated children. PCV7 also reduces nasopharyngeal carriage with pneumococcal vaccine serotypes. ${ }^{64}$ As a result of herd protection, decline in the rates of IPD was also observed in unvaccinated persons such as HIV-infected adults among which an $88 \%$ reduction in vaccine-type IPD was reported in the 7 years post-PCV7 introduction for children. ${ }^{67}$

In 2010, a 13-valent conjugate vaccine (PCV13 [Prevnar-13, Pfizer, New York, NY, USA]) replaced PCV7. PCV13 includes serotypes 1,3, 5, 6A, 7F, and19A in addition to the serotypes found in PCV7. These additional serotypes accounting for up to $61 \%$ of invasive disease before PCV13 replaced PCV7 in 2010, with 19A causing $43 \%$ of the cases. ${ }^{9}$ PCV13 
was shown to elicit similar antibody responses to those against the serotypes contained in PCV7 and induced very robust antibody responses to the 6 additional serotypes in the vaccine. Shortly after its implementation, PCV13 has resulted in dramatic reductions in IPD among children and, through herd protection, among adults. ${ }^{68,69}$ Since 2010 , incidence of overall IPD in the US declined by $64 \%$ and IPD caused by additional 6 serotypes in PCV13 declined by $93 \%$ among children younger than 5 years. Among unvaccinated adults, incidence of IPD overall also declined by $12-32 \%$ and IPD caused by PCV13 unique serotypes declined by $58-72 \%$, depending on age (Table 4). ${ }^{68} \mathrm{~A}$ randomized placebocontrolled trial (CAPiTA trial) among approximately 85,000 vaccinated adults aged $\ 65$ years demonstrated $45.6 \%$ efficacy of PCV13 against vaccine-type pneumococcal pneumonia, $45.0 \%$ efficacy against vaccine-type nonbacteremic pneumococcal pneumonia, and $75.0 \%$ efficacy against vaccine-type IPD among adults aged $\nsucceq 65$ years. ${ }^{70}$ In June 2014, ACIP recommended routine use of both PCV13 and PPSV23 in series to all adults aged $\ 65$ years. ${ }^{71}$

\section{Summary}

Universal immunization of infants and toddlers with PCVs over the past 15 years has dramatically altered the landscape of pneumococcal disease. Decreases in IPD, all cause pneumonia, empyema, mastoiditis, acute otitis media and complicated otitis media have been reported from multiple countries where universal immunization has been implemented. Introduction of childhood pneumococcal vaccines has also led to expanded understanding of pneumococcal disease: observations have confirmed that most pneumococci are transmitted from children to adults, and that pneumococcal serotypes are not equal in terms of common clinical syndromes, likelihood of antibiotic resistance, or likelihood of progression to disease once colonization occurs. Children with comorbid conditions have higher rates of pneumococcal disease and increased case fatality rates compared to otherwise healthy children, and protection for the most vulnerable pediatric patients will require new strategies to address the underlying host susceptibility and the expanded spectrum of serotypes observed.

\section{Acknowledgments}

Disclosures

Dr. Stephen I Pelton receives IIR research funding (through BUMC) from Pfizer, Inc and Merck Vaccines and Honorarium or consulting fees from Pfizer for activities related to pneumococcal conjugate vaccine/pneumococcal disease.

Dr. Kimberly M Shea receives IIR research funding (through BUMC) from Pfizer, Inc and consulting fees from Pfizer for activities related to pneumococcal diseases.

\section{References}

1. Jain S, Williams DJ, Arnold SR, et al. Community-acquired pneumonia requiring hospitalization among U.S. children. N Engl J Med. 2015; 372:835-845. [PubMed: 25714161]

2. Griffin M, Zhu Y, Moore M, Whitney C, Grijalva CUS. hospitalizations for pneumonia after a decade of pneumococcal vaccination. N Engl J Med. 2013; 369:155-163. [PubMed: 23841730] 
3. Dagan R, Givon-Lavi N, Zamir O, et al. Reduction of nasopharyngeal carriage of Streptococcus pneumoniae after administration of a 9-valent pneumococcal conjugate vaccine to toddlers attending day care centers. J Infect Dis. 2002; 185:927-936. [PubMed: 11920317]

4. Granat SM, Mia Z, Ollgren J, et al. Longitudinal study on pneumococcal carriage during the first year of life in Bangladesh. Pediatr Infect Dis J. 2007; 26:319-324. [PubMed: 17414395]

5. Ampofo, K.; Byington, C. Streptoccoccus pneumoniae. In: Long, SS.; Pickering, LK.; Prober, CG., editors. Principles and Practice of Pediatric Infectious Diseases. Philadelphia: Churchil Livingstone; 2012. p. 721-728.

6. Gray BM, Converse GM 3rd, Dillon HC Jr. Epidemiologic studies of Streptococcus pneumoniae in infants: acquisition, carriage, and infection during the first 24 months of life. J Infect Dis. 1980; 142:923-933. [PubMed: 7462701]

7. Centers for Disease Control abd Prevention (CDC). Preventing pneumococcal disease among infants and young children. Recommendations of the Advisory Committee on Immunization Practices (ACIP). MMWR. 2000; 49:1-35.

8. Yildirim I, Hanage WP, Lipsitch M, et al. Serotype specific invasive capacity and persistent reduction in invasive pneumococcal disease. Vaccine. 2010; 29:283-288. [PubMed: 21029807]

9. World Health Organization (WHO). Review of serotype replacement in the setting of 7-valent pneumococcal conjugate vaccine (PCV-7) use and implications for the PCV10/PCV13 era. Geneva, Switzerland: World Health Organization; 2012.

10. Robinson KA, Baughman W, Rothrock G, et al. Epidemiology of invasive Streptococcus pneumoniae infections in the United States, 1995-1998: Opportunities for prevention in the conjugate vaccine era. JAMA. 2001; 285:1729-1735. [PubMed: 11277827]

11. Cherian T, Steinhoff MC, Harrison LH, Rohn D, McDougal LK, Dick J. A cluster of invasive pneumococcal disease in young children in child care. JAMA. 1994; 271:695-697. [PubMed: 8309033]

12. Centers for Disease Control and Prevention (CDC). Invasive pneumococcal disease in young children before licensure of 13-valent pneumococcal conjugate vaccine - United States, 2007. MMWR. 2010; 59:253-257. [PubMed: 20224541]

13. Yildirim I, Stevenson A, Hsu KK, Pelton SI. Evolving picture of invasive pneumococcal disease in massachusetts children: a comparison of disease in 2007-2009 with earlier periods. PIDJ. 2012; 31:1016-1021.

14. Hoffman JA, Mason EO, Schutze GE, et al. Streptococcus pneumoniae infections in the neonate. Pediatrics. 2003; 112:1095-1102. [PubMed: 14595052]

15. Tsai CJ, Griffin MR, Nuorti JP, Grijalva CG. Changing epidemiology of pneumococcal meningitis after the introduction of pneumococcal conjugate vaccine in the United States. Clin Infect Dis. 2008; 46:1664-1672. [PubMed: 18433334]

16. Harboe ZB, Dalby T, Weinberger DM, et al. Impact of 13-valent pneumococcal conjugate vaccination in invasive pneumococcal disease incidence and mortality. Clin Infect Dis. 2014; 59:1066-1073. [PubMed: 25034421]

17. Centers for Disease Control and Prevention (CDC). Direct and indirect effects of routine vaccination of children with 7 -valent pneumococcal conjugate vaccine on incidence of invasive pneumococcal disease-United States, 1998-2003. MMWR. 2005; 54:893-897. [PubMed: 16163262]

18. Whitney CG, Farley MM, Hadler J, et al. Decline in invasive pneumococcal disease after the introduction of protein-polysaccharide conjugate vaccine. N Engl J Med. 2003; 348:1737-1746. [PubMed: 12724479]

19. Singleton RJ, Hennessy TW, Bulkow LR, et al. Invasive pneumococcal disease caused by nonvaccine serotypes among alaska native children with high levels of 7-valent pneumococcal conjugate vaccine coverage. JAMA. 2007; 297:1784-1792. [PubMed: 17456820]

20. Grall N, Hurmic O, Al Nakib M, et al. Epidemiology of Streptococcus pneumoniae in France before introduction of the PCV-13 vaccine. Eur J Clin Microbiol Infect Dis. 2011; 30:1511-1519. [PubMed: 21499971] 
21. Munoz-Almagro C, Jordan I, Gene A, Latorre C, Garcia-Garcia JJ, Pallares R. Emergence of invasive pneumococcal disease caused by nonvaccine serotypes in the era of 7-valent conjugate vaccine. Clin Infect Dis. 2008; 46:174-182. [PubMed: 18171247]

22. Grijalva CG, Nuorti JP, Zhu Y, Griffin MR. Increasing incidence of empyema complicating childhood community-acquired pneumonia in the United States. Clin Infect Dis. 2010; 50:805813. [PubMed: 20166818]

23. Byington CL, Korgenski K, Daly J, Ampofo K, Pavia A, Mason EO. Impact of the pneumococcal conjugate vaccine on pneumococcal parapneumonic empyema. PIDJ. 2006; 25:250-254.

24. Obando I, Arroyo LA, Sanchez-Tatay D, Moreno D, Hausdorff WP, Brueggemann AB. Molecular typing of pneumococci causing parapneumonic empyema in Spanish children using multilocus sequence typing directly on pleural fluid samples. PIDJ. 2006; 25:962-963.

25. Halgrimson WR, Chan KH, Abzug MJ, Perkins JN, Carosone-Link P, Simoes EA. Incidence of acute mastoiditis in Colorado children in the pneumococcal conjugate vaccine era. PIDJ. 2014; 33:453-457.

26. Bender JM, Ampofo K, Byington CL, et al. Epidemiology of Streptococcus pneumoniae-induced hemolytic uremic syndrome in Utah children. PIDJ. 2010; 29:712-716.

27. Lee CF, Liu SC, Lue KH, Chen JP, Sheu JN. Pneumococcal pneumonia with empyema and hemolytic uremic syndrome in children: report of three cases. Journal of microbiology, immunology, and infection = Wei mian yu gan ran za zhi. 2006; 39:348-352.

28. Moore MR, Link-Gelles R, Schaffner W, et al. Effect of use of 13-valent pneumococcal conjugate vaccine in children on invasive pneumococcal disease in children and adults in the USA: analysis of multisite, population-based surveillance. Lancet Infect Dis. 2015; 15:301-309. [PubMed: 25656600]

29. Pelton SI, Weycker D, Farkouh RA, Strutton DR, Shea KM, Edelsberg J. Risk of pneumococcal disease in children with chronic medical conditions in the era of pneumococcal conjugate vaccine. Clin Infect Dis. 2014; 59:615-623. [PubMed: 24825867]

30. Shea KM, Edelsberg J, Weycker D, Farkouh RA, Strutton DR, Pelton SI. Rates of pneumococcal disease in adults with chronic medical conditions. Open forum infectious diseases. 2014; 1:ofu024. [PubMed: 25734097]

31. Muhammad RD, Oza-Frank R, Zell E, et al. Epidemiology of invasive pneumococcal disease among high-risk adults since the introduction of pneumococcal conjugate vaccine for children. Clin Infect Dis. 2013; 56:e59-e67. [PubMed: 23155149]

32. Yildirim I, Shea KM, Little BA, Silverio AL, Pelton SI. Members of the Massachusetts Department of Public H. Vaccination, underlying comorbidities, and risk of invasive pneumococcal disease. Pediatrics. 2015; 135:495-503. [PubMed: 25647674]

33. Centers for Disease Control and Prevention (CDC). Use of 13-valent pneumococcal conjugate vaccine and 23-valent pneumococcal polysaccharide vaccine for adults with immunocompromising conditions: recommendations of the Advisory Committee on Immunization Practices (ACIP). MMWR. 2012; 61:816-819. [PubMed: 23051612]

34. O'Brien KL, Moulton LH, Reid R, et al. Efficacy and safety of seven-valent conjugate pneumococcal vaccine in American Indian children: group randomised trial. Lancet. 2003; 362:355-361. [PubMed: 12907008]

35. van Hoek AJ, Andrews N, Waight PA, et al. The effect of underlying clinical conditions on the risk of developing invasive pneumococcal disease in England. J Infect. 2012; 65:17-24. [PubMed: 22394683]

36. Inghammar M, Engstrom G, Kahlmeter G, Ljungberg B, Lofdahl CG, Egesten A. Invasive pneumococcal disease in patients with an underlying pulmonary disorder. Clin Microbiol Infect. 2013; 19:1148-1154. [PubMed: 23464817]

37. Reefhuis J, Honein MA, Whitney CG, et al. Risk of bacterial meningitis in children with cochlear implants. N Engl J Med. 2003; 349:435-445. [PubMed: 12890842]

38. Talbot TR, Hartert TV, Mitchel E, et al. Asthma as a risk factor for invasive pneumococcal disease. N Engl J Med. 2005; 352:2082-2090. [PubMed: 15901861] 
39. Ladhani SN, Slack MP, Andrews NJ, Waight PA, Borrow R, Miller E. Invasive pneumococcal disease after routine pneumococcal conjugate vaccination in children, England and Wales. Emerg Infect Dis. 2013; 19:61-68. [PubMed: 23259937]

40. Ladhani SN, Andrews NJ, Waight P, Borrow R, Slack MP, Miller E. Invasive pneumococcal disease, comorbidities, and polysaccharide vaccine use in children aged 5-15 years in England and Wales. Clin Infect Dis. 2014; 58:517-525. [PubMed: 24300040]

41. Rosenow EC. Studies in pneumonia and pneumococcus infection. J Infect Dis. 2004; 189:132-164. [PubMed: 14702163]

42. Coant PN, Kornberg AE, Duffy LC, Dryja DM, Hassan SM. Blood culture results as determinants in the organism identification of bacterial meningitis. Pediatr Emerg Care. 1992; 8:200-205. [PubMed: 1381091]

43. Neuman MI, Harper MB. Evaluation of a rapid urine antigen assay for the detection of invasive pneumococcal disease in children. Pediatrics. 2003; 112:1279-1282. [PubMed: 14654597]

44. Marcos MA, Martinez E, Almela M, Mensa J, Jimenez de Anta MT. New rapid antigen test for diagnosis of pneumococcal meningitis. Lancet. 2001; 357:1499-1500. [PubMed: 11377604]

45. Saha SK, Darmstadt GL, Yamanaka N, et al. Rapid diagnosis of pneumococcal meningitis: implications for treatment and measuring disease burden. PIDJ. 2005; 24:1093-1098.

46. Murdoch DR. Molecular genetic methods in the diagnosis of lower respiratory tract infections. APMIS. 2004; 112:713-727. [PubMed: 15638835]

47. Tzanakaki G, Tsopanomichalou M, Kesanopoulos K, et al. Simultaneous single-tube PCR assay for the detection of Neisseria meningitidis, Haemophilus influenzae type $\mathrm{b}$ and Streptococcus pneumoniae. Clin Microbiol Infect. 2005; 11:386-390. [PubMed: 15819865]

48. Seng P, Rolain JM, Fournier PE, La Scola B, Drancourt M, Raoult D. MALDI-TOF-mass spectrometry applications in clinical microbiology. Future microbiology. 2010; 5:1733-1754. [PubMed: 21133692]

49. Vernet G, Saha S, Satzke C, et al. Laboratory-based diagnosis of pneumococcal pneumonia: state of the art and unmet needs. Clin Microbiol Infect. 2011; 17(Suppl 3):1-13. [PubMed: 21457174]

50. Martinez RM, Bauerle ER, Fang FC, Butler-Wu SM. Evaluation of three rapid diagnostic methods for direct identification of microorganisms in positive blood cultures. J Clin Microbiol. 2014; 52:2521-2529. [PubMed: 24808235]

51. [Accessed July, 2015] http://www.accessdata.fda.gov/cdrh_docs/reviews/K130914.pdf

52. Altun O, Almuhayawi M, Ullberg M, Ozenci V. Rapid identification of microorganisms from sterile body fluids by use of FilmArray. J Clin Microbiol. 2015; 53:710-712. [PubMed: 25520440]

53. Werno AM, Murdoch DR. Medical microbiology: laboratory diagnosis of invasive pneumococcal disease. Clin Infect Dis. 2008; 46:926-932. [PubMed: 18260752]

54. Vuori-Holopainen E, Salo E, Saxen H, et al. Etiological diagnosis of childhood pneumonia by use of transthoracic needle aspiration and modern microbiological methods. Clin Infect Dis. 2002; 34:583-590. [PubMed: 11803504]

55. Tunkel AR, Hartman BJ, Kaplan SL, et al. Practice guidelines for the management of bacterial meningitis. Clin Infect Dis. 2004; 39:1267-1284. [PubMed: 15494903]

56 . Le J, Bradley JS, Murray W, et al. Improved vancomycin dosing in children using area under the curve exposure. PIDJ. 2013; 32:e155-e163.

57. Pelton, SI.; MR, J. Pneumococcal infections. In: Cherry, JD.; Harrision, GJ.; Kaplan, SL., editors. Feigin and Cherry's Textbook of Pediatric Infectious Diseases. 7 ed. Philadelphia: Elsevier Saunders; 2014. p. 1198-1246.

58. Committee on Infectious Diseases American Academy of Pediatrics. Pneumococcal Infections. In: Kimberlin; DW; Brady, Michael T.; Jackson, Anne Mary; Long, Sarah S., editors. Report of the Committee on Infectious Diseases. 30 ed. Elk Grove Village, IL: American Academy of Pediatrics; 2015. p. 638-644.

59. Schut ES, Brouwer MC, de Gans J, Florquin S, Troost D, van de Beek D. Delayed cerebral thrombosis after initial good recovery from pneumococcal meningitis. Neurology. 2009; 73:19881995. [PubMed: 19890068] 
60. Weinstein MP, Klugman KP, Jones RN. Rationale for revised penicillin susceptibility breakpoints versus Streptococcus pneumoniae: coping with antimicrobial susceptibility in an era of resistance. Clin Infect Dis. 2009; 48:1596-1600. [PubMed: 19400744]

61. Jackson LA, Neuzil KM. Plotkin SA, Orenstein WA, Offit PA. Pneumococcal polysaccharide vaccine. Vaccines (5th ed.). 2008:569-604.

62. Sanders LA, Rijkers GT, Kuis W, et al. Defective antipneumococcal polysaccharide antibody response in children with recurrent respiratory tract infections. J Allergy Clin Immunol. 1993; 91:110-119. [PubMed: 8423268]

63. Centers for Disease Control and Prevention (CDC). Prevention of Pneumococcal Disease Among Infants and Children:Use of 13-Valent Pneumococcal Conjugate Vaccine and 23-Valent Pneumococcal Polysaccharide Vaccine: Recommendations of the Advisory Committee on Immunization Practices (ACIP). MMWR. 2010; 59:1-18.

64. Black S, Shinefield H, Fireman B, et al. Efficacy safety immunogenicity of heptavalent pneumococcal conjugate vaccine in children. Northern California Kaiser Permanente Vaccine Study Center Group. Pediatr Infect Dis J. 2000; 19:187-195. [PubMed: 10749457]

65. World Health Organization (WHO). Pneumococcal conjugate vaccine for childhood immunizationWHO position paper. Wkly Epidemiol Rec. 2007; 12:93-104.

66. Grijalva C, Poehling K, Nuorti J, et al. National impact of universal childhood immunization with pneumococcal conjugate vaccine on outpatient medical care visits in the United States. Pediatrics. 2006; 118:865-873. [PubMed: 16950975]

67. Cohen A, Harrison L, Farley M, et al. Prevention of invasive pneumococcal disease among HIVinfected adults in the era of childhood pneumococcal immunization. AIDS. 2010; 24:2253-2262. [PubMed: 20671543]

68. Moore MR, Link-Gelles R, Schaffner W, et al. Effect of use of 13-valent pneumococcal conjugate vaccine in children on invasive pneumococcal disease in children and adults in the USA: analysis of multisite, population-based surveillance. Lancet Infect Dis. 2015; 15:301-309. [PubMed: 25656600]

69. Kaplan S, Barson W, Lin P, et al. Early trends for invasive pneumococcal infections in children after the introduction of the 13-valent pneumococcal conjugate vaccine. PIDJ. 2013; 32:203-207.

70. Bonten M, Huijts S, Bolkenbaas M, et al. Polysaccharide Conjugate Vaccine against Pneumococcal Pneumonia in Adults. N Engl J Med. 2015; 372:1114-1125. [PubMed: 25785969]

71. Centers for Disease Control and Prevention (CDC). Use of 13-Valent Pneumococcal Conjugate Vaccine and 23-Valent Pneumococcal Polysaccharide Vaccine Among Adults Aged $\ 65$ years: Recommendations of the Advisory Committee on Immunization Practices (ACIP). MMWR. 2014; 63:822-825. [PubMed: 25233284] 


\section{KEY POINTS}

1. Universal immunization of infants and toddlers with pneumococcal conjugate vaccines has resulted in decreases in IPD, all cause pneumonia, empyema, mastoiditis, acute otitis media and complicated otitis media

2. The impact of pneumococcal conjugate vaccine extends beyond those immunized to children too young to be immunized, children unable to respond to the vaccine and adults in the community as a result of herd effect.

3. Children with comorbid conditions have higher rates of pneumococcal disease and increased case fatality rates compared to otherwise healthy children.

4. Treatment of pneumococcal disease requires an approach that considers site of infection, antimicrobial susceptibility patterns in the community and severity of illness 


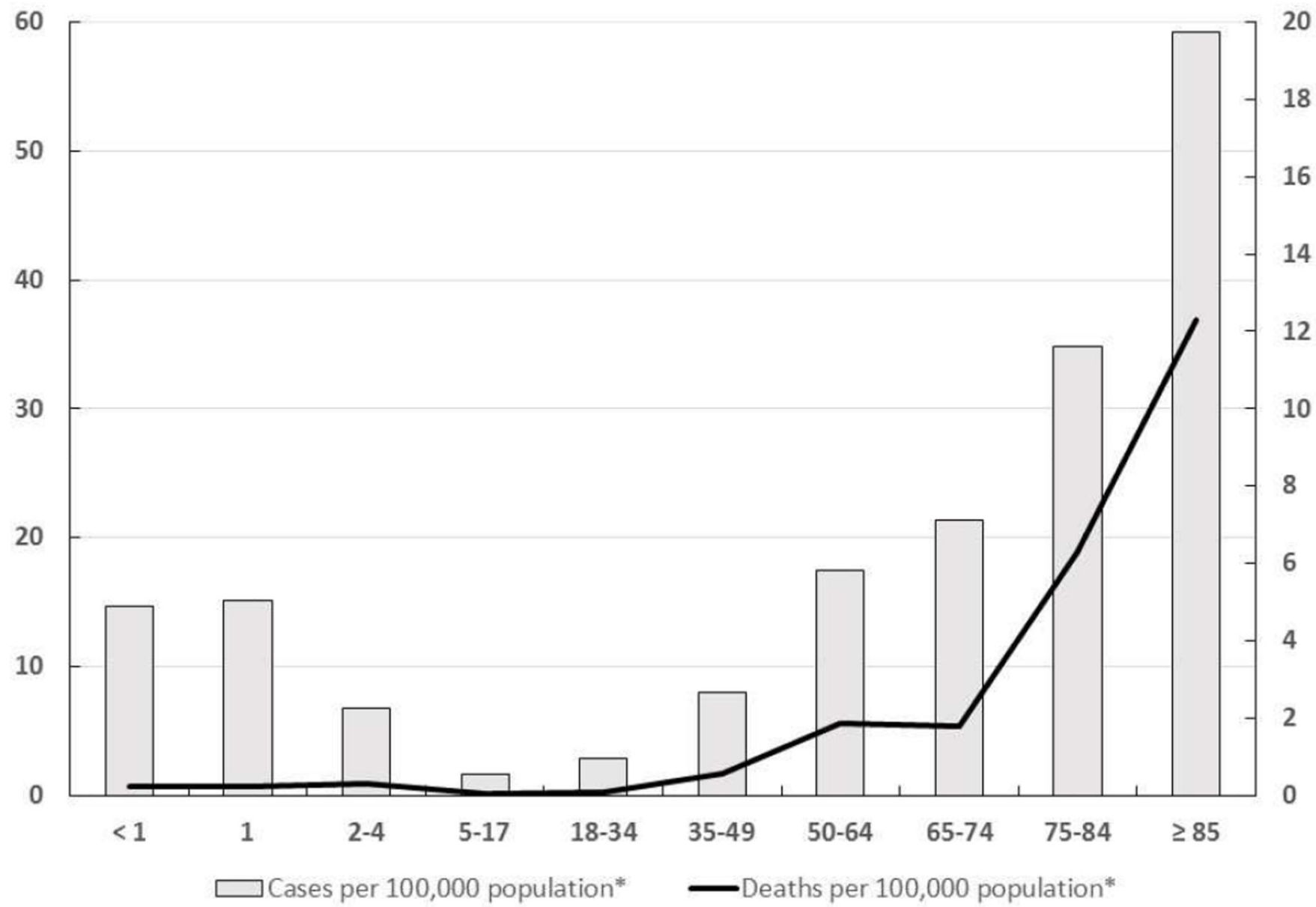

Figure 1.

Rates of pneumococcal disease by age groups in United States, 2013. Redrawn from Centers for Disease control and prevention, Active Bacterial core Surveillance (ABCs)/Emerging Infections Programs network (EIP), 2013. http://www.cdc.gov/abcs/reports-findings/ survreports/spneu13.html (*ABC population areas) 

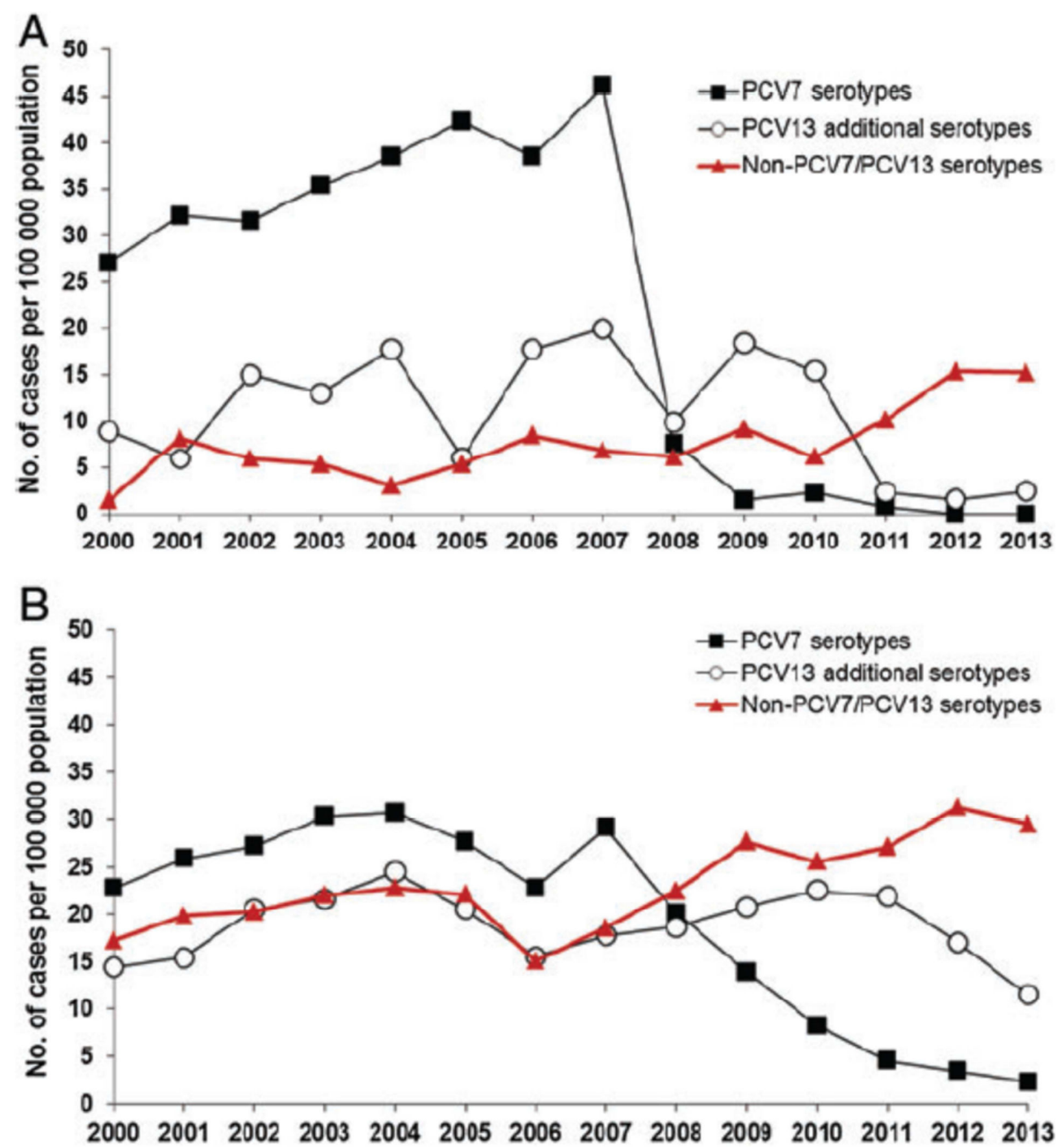

Figure 2.

Incidence of IPD by age group and serotype grouping in Denmark. A. Danish children less than 2 years of age B. Danish adults $\geq 65$ years of age. PCV7 was introduced in 2007 and PCV13 in 2010. (From Harboe ZB, Dalby T, Weinberger DM, et al. Impact of 13-valent pneumococcal conjugate vaccination in invasive pneumococcal disease incidence and mortality. Clin Infect Dis 2014; 59: 1066-73.) 


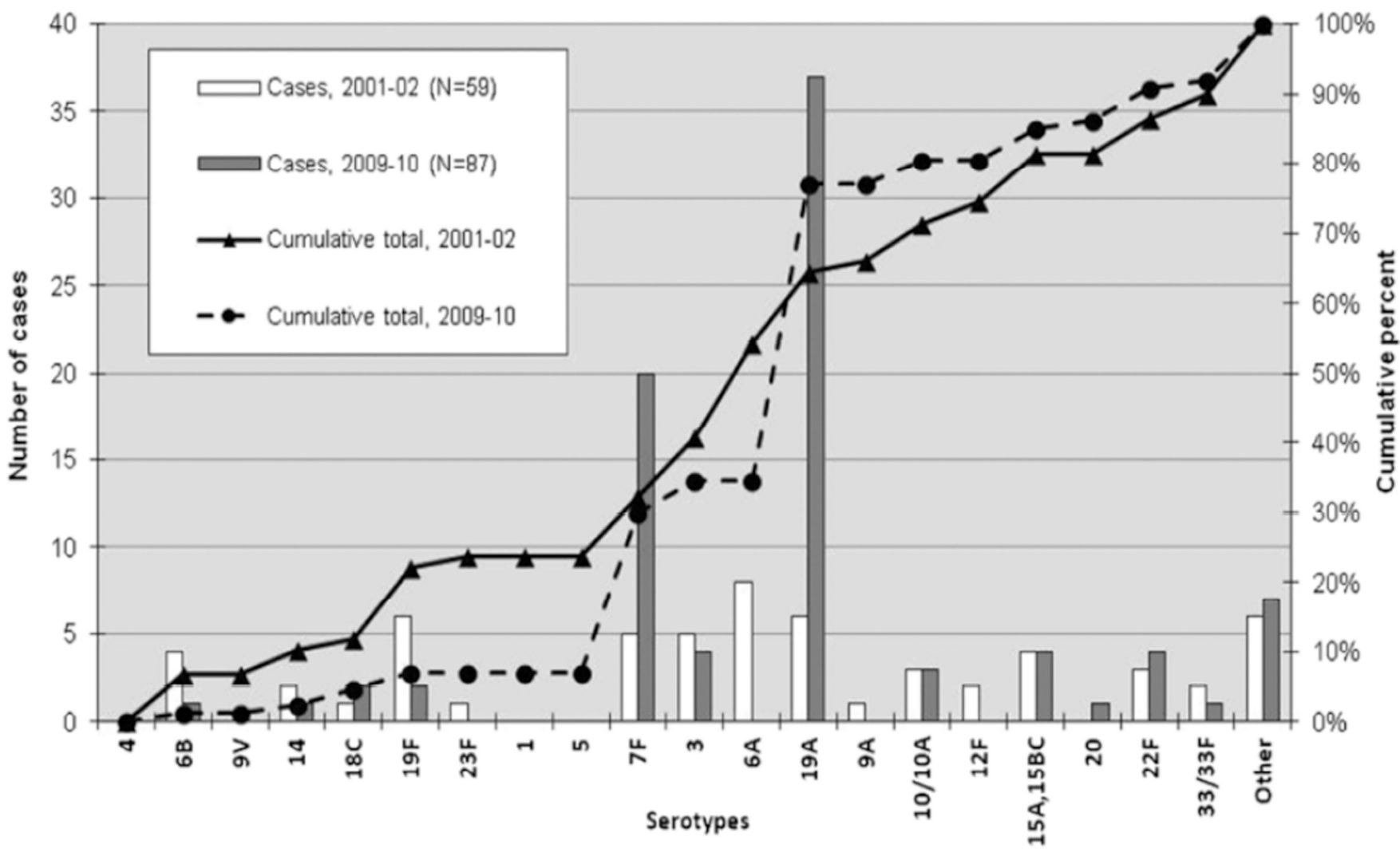

Figure 3.

Serotypes causing invasive pneumococcal disease in children $<18$ years of age in Massachusetts, comparison of 2001 to 2002 and 2009 to 2010. (From Yildirim I, Stevenson A, Hsu KK, Pelton SI. Evolving picture of invasive pneumococcal disease in Massachusetts children: a comparison of disease in 2007-2009 with earlier periods. PIDJ 2012; 31(10): 1016-21.) 


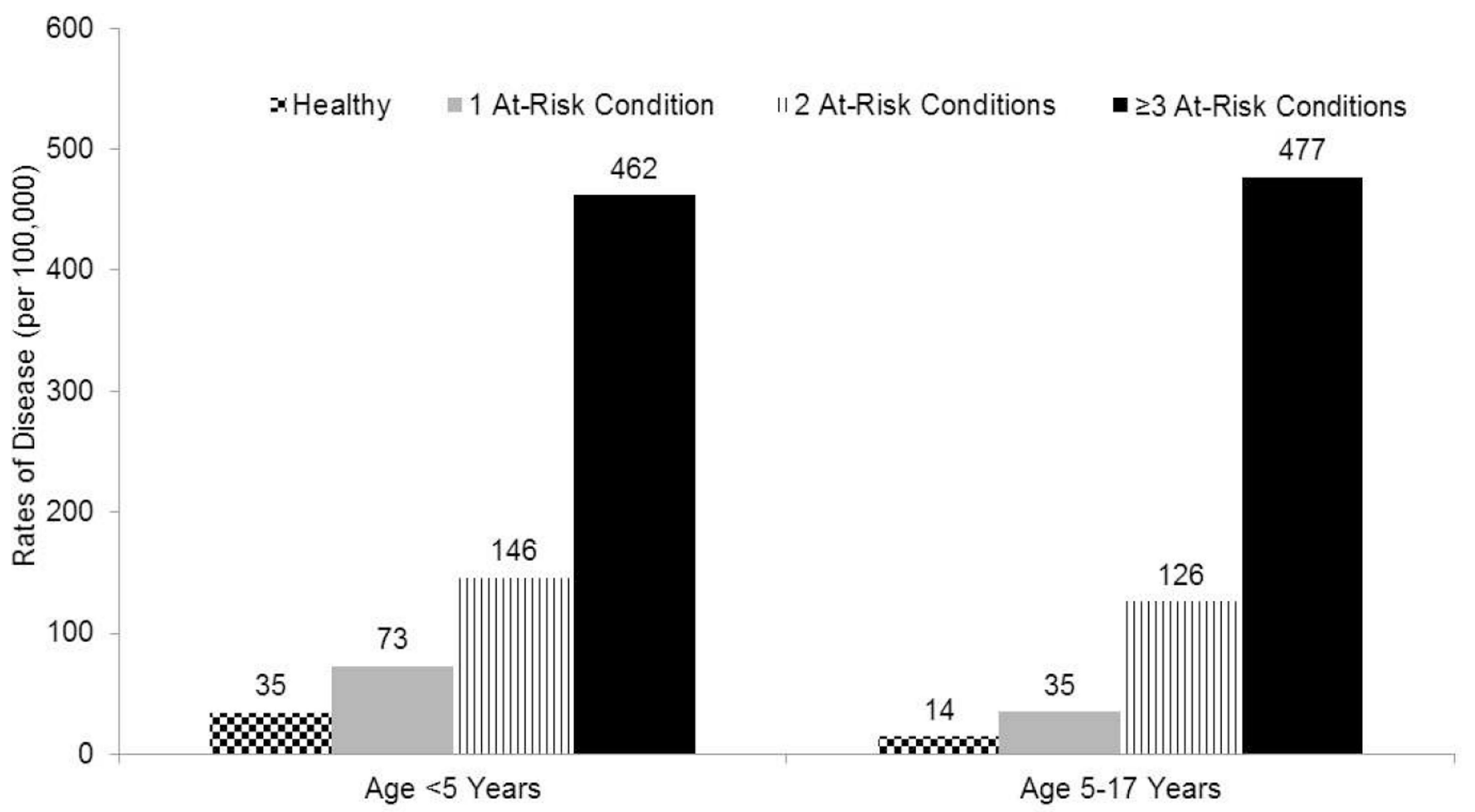

Figure 4.

Rates of pneumococcal pneumonia in children with at risk conditions compared to otherwise healthy children. (Modified from Pelton SI, Weycker D, Farkouh RA, et al. Risk of pneumococcal disease in children with chronic medical conditions in the era of pneumococcal conjugate vaccine. Clin Infect Dis, 2014;59:615-23.) 

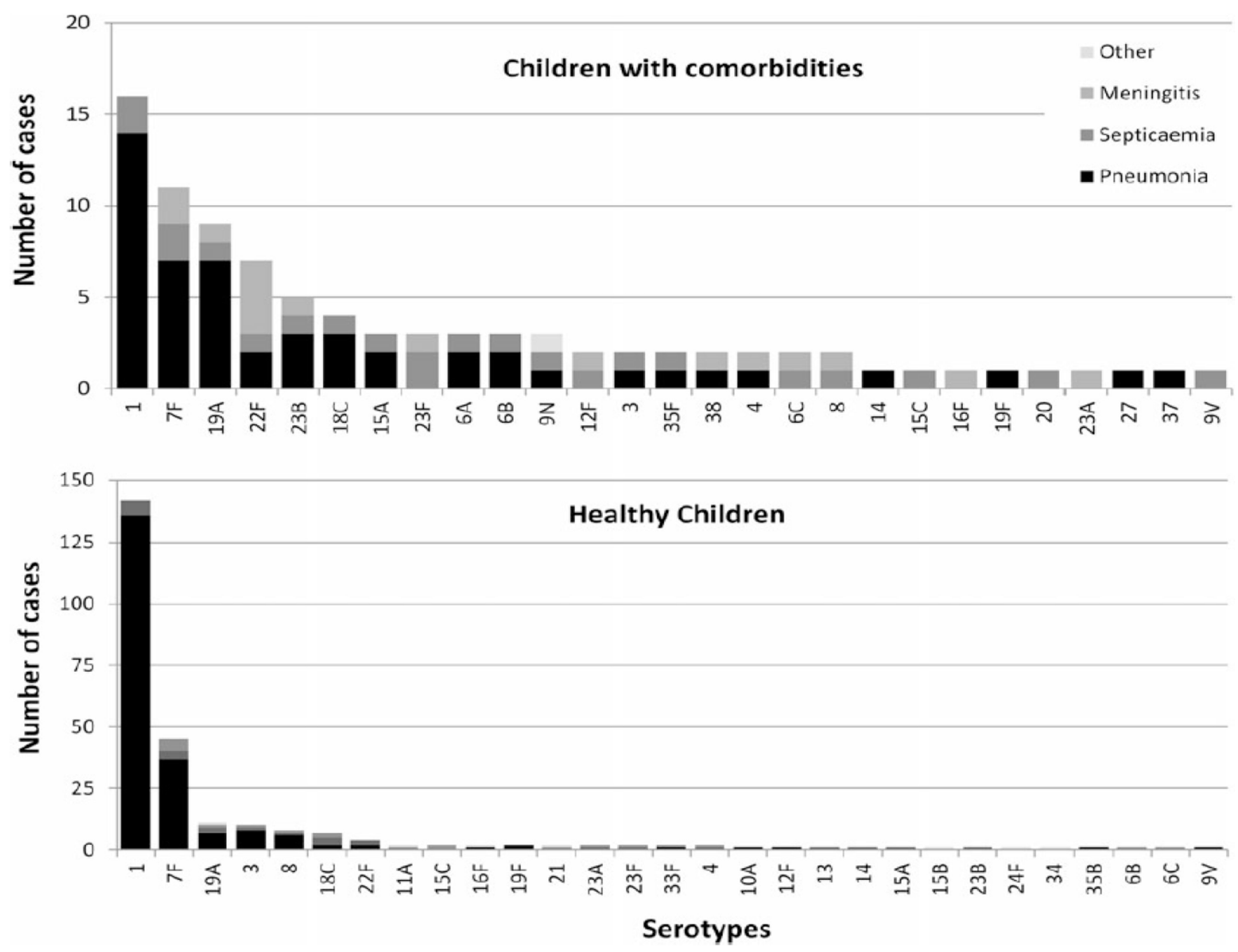

Figure 5.

Serotype distribution in invasive pneumococcal disease in children 5-15 yrs. with and without comorbidity. (From Modified from Ladhani SN, Andrews NJ, Waight P, Borrow R, Slack MP, Miller E. Invasive pneumococcal disease, comorbidities, and polysaccharide vaccine use in children aged 5-15 years in England and Wales. Clin Infect Dis 2014;58:517-25.) 


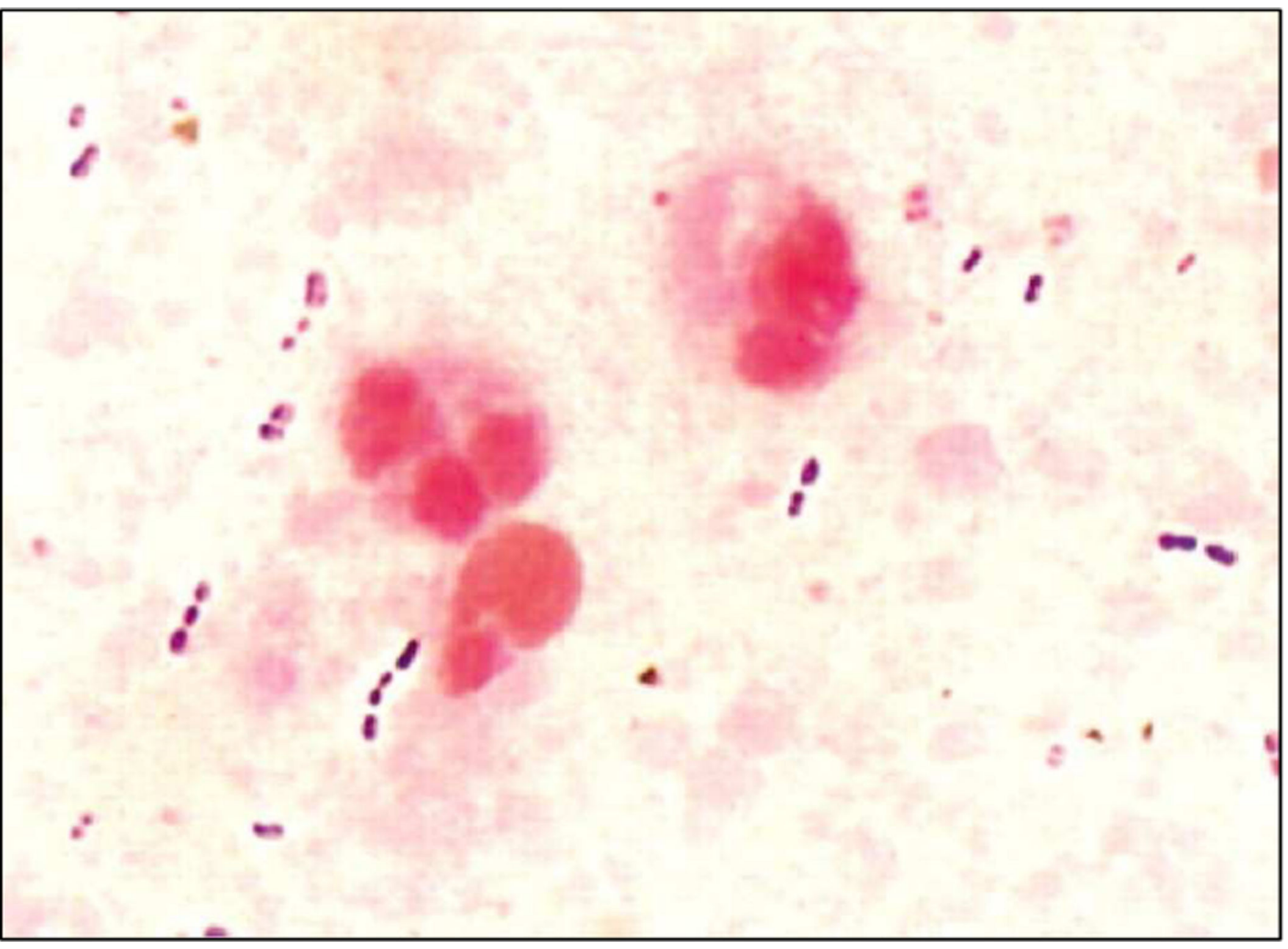

Figure 6.

Gram stain of a sputum sample showing Streptococcus pneumoniae as gram-positive diplococci (From Werno AM, Murdoch DR. Medical microbiology: laboratory diagnosis of invasive pneumococcal disease. Clin Infect Dis 2008;46:926-32.) 
Table 1

Antibiotic dosing appropriate for pneumococcal meningitis (Modified from Pelton SI, MR J. Pneumococcal infections. In: Cherry JD, Harrison GJ, Kaplan SL, eds. Feigin and Cherry's Textbook of Pediatric Infectious Diseases. 7 ed. Philadelphia: Elsevier Saunders; 2014:1198-246.)

\begin{tabular}{|c|c|c|c|}
\hline \multirow{2}{*}{ Antimicrobial agent } & \multicolumn{2}{|c|}{$\begin{array}{c}\text { Total daily dose (number of doses per } \\
\text { day) }\end{array}$} & \multirow{2}{*}{$\begin{array}{c}\text { Susceptible } \\
\text { breakpoint }(\mu \mathrm{g} / \mathrm{mL})^{a}\end{array}$} \\
\hline & Adolescents & Infants and children & \\
\hline \multicolumn{4}{|l|}{ Parenteral agents } \\
\hline Penicillin G & 24 million units & $\begin{array}{l}300,000-400,000 \\
\text { units } / \mathrm{kg}\end{array}$ & $\$) .06$ \\
\hline Ampicillin & $12 \mathrm{~g}$ & $300 \mathrm{mg} / \mathrm{kg}$ & Penicillin $₫ .06$ \\
\hline Ceftriaxone & $4 \mathrm{~g}$ & $100 \mathrm{mg} / \mathrm{kg}$ & $\unlhd) .5$ \\
\hline Cefotaxime & $8-12 \mathrm{~g}$ & $225-300 \mathrm{mg} / \mathrm{kg}$ & $\$) .5$ \\
\hline Rifampin & $600 \mathrm{mg}$ & $20 \mathrm{mg} / \mathrm{kg}$ & $\$) .5$ \\
\hline Meropenem & $6 \mathrm{~g}$ & $120 \mathrm{mg} / \mathrm{kg}$ & $\$) .25$ \\
\hline Vancomycin ${ }^{*}$ & $30-45 \mathrm{mg} / \mathrm{kg}$ & $70-80 \mathrm{mg} / \mathrm{kg}$ & \\
\hline
\end{tabular}

${ }^{a}$ Susceptibility breakpoint for agent shown unless specified otherwise,

* Dosing should be adjusted to achieve trough concentrations of 15-20 ug/ml for CNS infection. 


\section{Table 2}

Specific recommendations for antimicrobial selection in pneumococcal meningitis based on penicillin and ceftriaxone susceptibility. (Modified from AR Tunkel, et al. Practice Guidelines for the Management of Bacterial Meningitis. Clin Infect Dis 2004; 39:1267-84)

\begin{tabular}{|ccc|}
\hline Susceptibility & Standard therapy & Alternative therapies \\
\hline Penicillin MIC & Penicillin G or ampicillin \\
$<0.1 \mu \mathrm{g} / \mathrm{mL}$ & $\begin{array}{c}\text { Third-generation cephalosporin, }{ }^{a} \\
\text { chloramphenicol }\end{array}$ \\
$0.1-1.0 \mu \mathrm{g} / \mathrm{mL}^{b}$ & $\begin{array}{c}\text { Third-generation } \\
\text { cephalosporin }\end{array}$ \\
& $\begin{array}{c}\text { Vancomycin plus a third- } \\
\text { generation cephalosporina, }\end{array}$ & Cefepime, meropenem \\
$2.0 \mu \mathrm{g} / \mathrm{mL}$ & Fluoroquinolone $^{d}$ \\
\hline Cefotaxime or ceftriaxone MIC & \\
\hline $1.0 \mu \mathrm{g} / \mathrm{mL}$ & $\begin{array}{r}\text { Vancomycin plus a third- } \\
\text { generation cephalosporina, }{ }^{c}\end{array}$ & Fluoroquinolone ${ }^{d}$ \\
\hline
\end{tabular}

${ }^{a}$ Ceftriaxone or cefotaxime,

${ }^{b}$ Ceftriaxone/cefotaxime-susceptible isolates,

${ }^{c}$ Consider addition of rifampin if the MIC of ceftriaxone is $12 \mathrm{mg} / \mathrm{mL}$,

$d_{\text {Gatifloxacin or moxifloxacin. }}$ 
Table 3

Medical conditions or other indications for administration of PCV13, ${ }^{*}$ and indications for PPSV2 $3^{\dagger}$ administration and revaccination for children aged 6-18 years ${ }^{\S}$ (From Centers for Disease Control and Prevention (CDC). Use of 13-Valent Pneumococcal Conjugate Vaccine and 23-Valent Pneumococcal Polysaccharide Vaccine Among Children Aged 6-18 Years with Immunocompromising Conditions: Recommendations of the Advisory Committee on Immunization Practices (ACIP). MMWR 2013; 62: 521524)

\begin{tabular}{|c|c|c|c|c|}
\hline \multirow{2}{*}{ Risk group } & \multirow{2}{*}{ Underlying medical condition } & \multirow{2}{*}{$\begin{array}{c}\text { PCV13 } \\
\text { Recommended }\end{array}$} & \multicolumn{2}{|c|}{ PPSV23 } \\
\hline & & & Recommended & Revaccination 5 yrs \\
\hline \multirow{8}{*}{$\begin{array}{l}\text { Immunocompetent } \\
\text { Persons }\end{array}$} & Chronic heart disease $\mathrm{I}^{I}$ & & $\checkmark$ & \\
\hline & Chronic lung disease ${ }^{* *}$ & & $\checkmark$ & \\
\hline & Diabetes mellitus & & $\checkmark$ & \\
\hline & Cerebrospinal fluid leaks & $\checkmark$ & $\checkmark$ & \\
\hline & Cochlear implants & $\checkmark$ & $\checkmark$ & \\
\hline & Alcoholism & & $\checkmark$ & \\
\hline & Chronic liver disease & & $\checkmark$ & \\
\hline & Cigarette smoking & & $\checkmark$ & \\
\hline \multirow{2}{*}{$\begin{array}{l}\text { Persons with functional } \\
\text { or anatomic asplenia }\end{array}$} & $\begin{array}{l}\text { Sickle cell disease/other } \\
\text { hemaglobinopathies }\end{array}$ & $\checkmark$ & $\checkmark$ & $\checkmark$ \\
\hline & Congenital or acquired asplenia & $\checkmark$ & $\sqrt{ }$ & $\checkmark$ \\
\hline \multirow{11}{*}{$\begin{array}{l}\text { Immunocompromised } \\
\text { persons }\end{array}$} & $\begin{array}{l}\text { Congenital or acquired } \\
\text { immunodeficiencies }{ }^{\dagger \dagger}\end{array}$ & $\checkmark$ & $\checkmark$ & $\checkmark$ \\
\hline & $\begin{array}{l}\text { Human immunodeficiency virus } \\
\text { infection }\end{array}$ & $\checkmark$ & $\sqrt{ }$ & $\sqrt{ }$ \\
\hline & Chronic renal failure & $\checkmark$ & $\checkmark$ & $\checkmark$ \\
\hline & Nephrotic syndrome & $\checkmark$ & $\checkmark$ & $\checkmark$ \\
\hline & Leukemia & $\checkmark$ & $\checkmark$ & $\checkmark$ \\
\hline & Lymphoma & $\checkmark$ & $\checkmark$ & $\checkmark$ \\
\hline & Hodgkin disease & $\checkmark$ & $\checkmark$ & $\checkmark$ \\
\hline & Generalized malignancy & $\checkmark$ & $\checkmark$ & $\checkmark$ \\
\hline & $\begin{array}{l}\text { Iatrogenic } \\
\text { immunosuppression } \$ \S\end{array}$ & $\checkmark$ & $\checkmark$ & $\checkmark$ \\
\hline & Solid organ transplant & $\checkmark$ & $\checkmark$ & $\checkmark$ \\
\hline & Multifile myeloma & $\checkmark$ & $\checkmark$ & $\checkmark$ \\
\hline
\end{tabular}

(*13-valent pneumococcal conjugate vaccine.

${ }^{\dagger} 23$-valent pneumococcal polysaccharide vaccine.

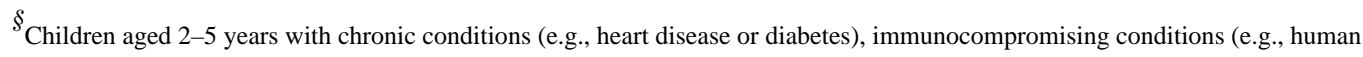
immunodeficiency virus), functional or anatomic asplenia (including sickle cell disease), cerebrospinal fluid leaks, or cochlear implants, and who have not previously received PCV13, have been recommended to receive PCV13 since 2010.

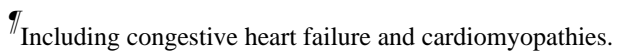

**

Including chronic obstructive pulmonary disease, emphysema, and asthma. 
${ }^{\dagger \dagger}$ Includes B-(humoral) or T-lymphocyte deficiency, complement deficiencies (particularly C1, C2, C3, and C4 deficiencies), and phagocytic disorders (excluding chronic granulomatous disease).

$\S \S$ Diseases requiring treatment with immunosuppressive drugs, including long-term systemic corticosteroids and radiation therapy.) 


\section{Table 4}

Difference between incidence expected in the absence of PCV13 and that noted after introduction of the vaccine. (From Moore MR, Link-Gelles R, Schaffner W, et al. Effect of use of 13-valent pneumococcal conjugate vaccine in children on invasive pneumococcal disease in children and adults in the USA: analysis of multisite, population-based surveillance. Lancet Infect Dis 2015; 15: 301-9)

\begin{tabular}{|c|c|c|c|}
\hline & 2010-11* & 2011-12* & 2012-13* \\
\hline \multicolumn{4}{|l|}{$<5$ years } \\
\hline All & $-45 \%(-50$ to -40$)$ & $-58 \%(-63$ to -53$)$ & $-64 \%$ (-68 to-59) \\
\hline PCV13 minus PCV7 & $-66 \%(-70$ to -61$)$ & $-88 \%$ (-89 to -86$)$ & $-93 \%$ (-94 to-91) \\
\hline Non-PCV13 & $-4 \%(-16$ to 12$)$ & $7 \%$ ( -9 to 31$)$ & $-2 \%(-19$ to 27$)$ \\
\hline \multicolumn{4}{|l|}{ 5-17 years } \\
\hline All & $-33 \%(-45$ to -18$)$ & $-36 \%(-49$ to -16$)$ & $-53 \%(-64$ to -35$)$ \\
\hline PCV13 minus PCV7 & $-33 \%(-45$ to -21$)$ & $-59 \%$ (-66 to- -48$)$ & $-75 \%$ (-80 to- 67$)$ \\
\hline Non-PCV13 & $-11 \%(-31$ to 25$)$ & $32 \%(-2$ to 110$)$ & $-2 \%(-32$ to 80$)$ \\
\hline \multicolumn{4}{|l|}{$18-49$ years } \\
\hline All & $-12 \%(-20$ to -5$)$ & $-37 \%(-43$ to -30$)$ & $-32 \%(-40$ to -22$)$ \\
\hline PCV13 minus PCV7 & $-33 \%(-38$ to -26$)$ & $-64 \%$ ( -68 to -60$)$ & $-72 \%$ ( -75 to -69$)$ \\
\hline Non-PCV13 & $3 \%(-6$ to 15$)$ & $-10 \%$ ( -20 to 4$)$ & $13 \%$ ( -2 to 34 ) \\
\hline \multicolumn{4}{|l|}{ 50-64 years } \\
\hline All & $-8 \%(-14$ to -2$)$ & $-28 \%(-33$ to -22$)$ & $-18 \%(-26$ to -10$)$ \\
\hline PCV13 minus PCV7 & $-23 \%(-28$ to -18$)$ & $-54 \%(-57$ to -50$)$ & $-62 \%(-65$ to -59$)$ \\
\hline Non-PCV13 & $8 \%(0$ to 18$)$ & $0 \%$ ( -9 to 12 ) & $26 \%$ (13 to 44$)$ \\
\hline \multicolumn{4}{|l|}{$\Varangle 65$ years } \\
\hline All & $-6 \%(-14$ to 3$)$ & $-19 \%(-27$ to -9$)$ & $-12 \%(-22$ to 1$)$ \\
\hline PCV13 minus PCV7 & $-23 \%$ ( -31 to -13$)$ & $-46 \%(-52$ to- -39$)$ & $-58 \%(-64$ to -52$)$ \\
\hline Non-PCV13 & $1 \%(-6$ to 10$)$ & $-7 \%(-15$ to 3$)$ & $7 \%(-4$ to 20$)$ \\
\hline
\end{tabular}

Data are difference in incidence (95\% interval estimate). PCV7=seven-valent pneumococcal conjugate vaccine. PCV13=13-valent pneumococcal conjugate vaccine.

* July 1 to June 30. 